\title{
Análisis del desarrollo institucional desde el enfoque institucional histórico*
}

\section{Analysis of Institutional Development from the Historical Institutionalist Approach}

\author{
Saúl Saavedra Echeverry ${ }^{* *}$
}

Recibido: 16 de diciembre 2015

Aprobado: 9 marzo de 2016

Disponible en línea: 30 de junio de 2016

\section{Resumen}

En el estudio del desarrollo de las instituciones políticas, los académicos que hoy trabajan con el enfoque institucionalista histórico vienen introduciendo en sus marcos de análisis conceptos, tales como el tiempo, los contextos, las coaliciones políticas y las ideas. Su interés es tratar de conectarlos en estudios de caso, que tienen como objeto comprender y explicar la estabilidad y el cambio en la vida política. Estas dos últimas dimensiones no las conciben separadas del desarrollo institucional, pues los mecanismos que propician la estabilidad son los mismos que generan el cambio. Las indagaciones que se inspiran en las principales ideas fuerza del institucionalismo histórico pueden enriquecerse con los aportes del institucionalismo discursivo, novedoso programa de investigación institucionalista que subraya la influencia de las ideas (el discurso y la comunicación) en el desarrollo

\section{Abstract}

In the study of the development of political institutions, scholars now working with the historical institutionalist approach are putting into their analytical frameworks concepts such as time, contexts, political coalitions and ideas. Their interest is to try to connect them in case studies intended to understand and explain stability and change in political life. The latter two dimensions are not conceived apart from institutional development, since the mechanisms that promote stability are the same that generate change. Inquiries inspired by the key ideas of historical institutionalism could be enriched by the contributions of discursive institutionalism, a new institutionalist research program that emphasizes the influence of ideas (discourse and communication) on institutional development. For discursive institutionalism institutions change by the impact of ideas, both for their

doi:10.11144/Javeriana.papo21-1.adie

${ }^{*}$ Artículo de revisión.

** Magíster en Estudios Políticos por la Pontificia Universidad Javeriana, doctor en Ciencias Políticas y Sociología por la Universidad Nacional de Educación a Distancia (UNED) (Madrid, España). Profesor asociado de la Escuela Superior de Administración Pública (ESAP) (Valle del Cauca). Correo electrónico: sausaavedra@hotmail.com 
institucional. Para el institucionalismo discursivo, las instituciones cambian por el efecto de las ideas, tanto por el contenido sustantivo de estas como por el proceso interactivo del discurso. La coordinación política, la comunicación y la deliberación que acompañan a la actividad pública tienen una dimensión discursiva.

\section{Palabras clave}

desarrollo institucional; institucionalismo histórico; institucionalismo discursivo; estabilidad y cambio institucional

\section{Cómo citar este artículo:}

Saavedra-Echeverry, S. (2016). Análisis del desarrollo institucional desde el enfoque institucional histórico. Papel Político, 21(1), 81-100. http://dx.doi.org/10.11144/Javeriana. papo21-1.adie substantive content and for the interactive process of discourse. Policy coordination, communication and deliberation that accompanies public activity have a discursive dimension.

\section{Keywords}

institutonal development; historical institutionalism; discursive institutionalism; institutional stability and change 


\section{Introducción}

En el análisis institucional, la permanencia y el cambio de las instituciones son temas que despiertan grandes controversias. En términos generales, en el institucionalismo histórico, ${ }^{1}$ enfoque analítico en el cual se ubica la presente reflexión, la discusión tiende a polarizarse en dos posiciones: en primer lugar, la que subraya la estabilidad como la característica predominante del desarrollo de las instituciones, que las acompaña la mayor parte del tiempo una vez ellas han logrado iniciar exitosamente una trayectoria determinada. Para la anterior posición, el cambio institucional es un fenómeno muy raro y, cuando se presenta como consecuencia de un factor exógeno, su duración es muy corta (Krasner et al., 1984; Pierson, 2000, 2004; North, 1994, 2001).

En segundo lugar, la posición que le da un carácter fluido al desarrollo institucional a causa del predominio que tienen en él los procesos de apertura, contingencia y agencia sobre los de cierre (Orren y Skowronek, 1999). Entre las dos posiciones se cruza una tercera, que defiende la idea de la estabilidad y el cambio como dos dimensiones inseparables del desarrollo institucional (Thelen, 1999, 2006; Thelen y Streck 2005; Mahoney y Thelen, 2009) (cuadro 1).

\section{Cuadro 1. La estabilidad y el cambio en varias corrientes del institucionalismo histórico}

\begin{tabular}{|l|l|l|l|}
\hline Enfoques & $\begin{array}{l}\text { Retornos crecientes } \\
\text { (Krasner, Pierson, North) }\end{array}$ & $\begin{array}{l}\text { Cambio fluido } \\
\text { (Orren y Skowronek) }\end{array}$ & $\begin{array}{l}\text { Retornos y cambios } \\
\text { crecientes } \\
\text { (Thelen y Majoney) }\end{array}$ \\
\hline Estabilidad & $\begin{array}{l}\text { Es la característica } \\
\text { predominante en las } \\
\text { instituciones }\end{array}$ & $\begin{array}{l}\text { Es una característica } \\
\text { de las instituciones, } \\
\text { pero subordinada a las } \\
\text { dinámicas del cambio }\end{array}$ & $\begin{array}{l}\text { Es una dimensión del } \\
\text { desarrollo institucional } \\
\text { inseparable del cambio }\end{array}$ \\
\hline Cambio & $\begin{array}{l}\text { Es una característica rara } \\
\text { y pasajera del desarrollo } \\
\text { institucional }\end{array}$ & $\begin{array}{l}\text { Es la característica } \\
\text { predominante de las } \\
\text { instituciones }\end{array}$ & $\begin{array}{l}\text { Es una dimensión } \\
\text { institucional inseparable } \\
\text { de la estabilidad }\end{array}$ \\
\hline
\end{tabular}

Fuente: elaboración propia

Para tratar la discusión en este artículo, se describen: 1) los principales énfasis del enfoque institucional histórico y las características del método histórico comparativo, 2) se revisan los argumentos de Vivien Schmidt sobre los aportes de una vertiente discursiva del institucionalismo y su impacto en la lógica del institucionalismo histórico, 3) se presentan los principales planteamientos sobre la estabilidad y el cambio institucional

\footnotetext{
${ }^{1}$ La expresión institucionalismo histórico se utiliza por primera vez en 1989, en el seminario realizado en Boulder (Colorado), que contó con la participación de varios de los académicos citados en este artículo. Producto del seminario fue el libro Structuring politics: Historical institutionalism in comparative analysis (1992).
} 
que formulan autores situados en diferentes posiciones dentro del institucionalismo histórico y 4) se hacen unas consideraciones finales.

\section{Principales énfasis del institucionalismo histórico}

El institucionalismo histórico es la primera versión del nuevo institucionalismo, que, según Peters (2003, p. 10), nace dentro de la ciencia política. Hoy, es un cuerpo de ideas coherente de investigación en dicha disciplina, que tiene como objetivo central realizar una comprensión profunda y contextualizada de los procesos de formación y cambio de las instituciones políticas a lo largo del tiempo, es decir, procesos temporales concretos. Su principal apuesta es entender y explicar los resultados de la acción política (Thelen, 1999, 2006; Steinmo, 2001; Pierson y Skocpol, 2008). Los siguientes son sus énfasis más destacados.

\section{Los problemas sustantivos del mundo real de la política}

Interroga sobre los orígenes y las variaciones de patrones, los eventos o los arreglos institucionales importantes en conexión con el contexto político y social (Pierson y Skocpol, 2008). Su objetivo es elaborar argumentos que ayuden a entender cómo y por qué las estructuras políticas condicionan la vida de los ciudadanos, restringen y canalizan su comportamiento. Sin caer en posiciones deterministas, plantea la existencia de posibilidades de acción que dejan un amplio margen para que los actores, que no son simples cumplidores de reglas o normas culturales institucionalizadas, elijan entre diferentes opciones tácticas y estratégicas, con el fin de alcanzar objetivos preconcebidos (Scharpf, 1997; Zurbriggen, 2006). En consecuencia, los académicos que trabajan con el enfoque institucionalista histórico tienden preferentemente a preguntarse ¿̇por qué determinadas estructuras institucionales logran institucionalizarse en algunos momentos y lugares mientras que en otros no? ¿Cómo organizaciones parecidas desarrollan características divergentes de evolución? ¿Qué efectos producen en un sistema político determinado organizaciones con diferentes niveles de institucionalización? ¿Cómo los actores se configuran históricamente? ¿Cómo definen sus preferencias y percepciones? ¿Cómo construyen sus capacidades estratégicas? (Thelen, 1999; Pierson y Skocpol, 2008).

\section{El análisis de los patrones institucionales a lo largo del tiempo}

El cultivo del análisis histórico, es decir, el rastreo sistemático del desarrollo institucional a lo largo del tiempo les permite a los institucionalistas históricos: 1) incluir en la agenda de investigación temas o problemas macro de larga duración (de décadas o siglos) y 2) evidenciar relaciones temporales particulares entre variables, donde las instituciones que precedieron a otras en el tiempo tienen la posibilidad de incidir en su 
desarrollo futuro. ${ }^{2}$ La postulación de la historia como variable explicativa del desarrollo institucional es acompañada con argumentos presentes en conceptos duros y blandos de path dependence ${ }^{3}$ secuencias ${ }^{4}$ y coyunturas críticas ${ }^{5}$ (Krasner et al., 1984; Pierson, 2000, 2004; Thelen, 1999, 2006; Thelen y Streck, 2005). Lo más relevante, más allá de los acuerdos y desacuerdos que circulan en la literatura institucionalista, es que dichos conceptos favorecen la inclusión en los marcos de análisis, de las dimensiones temporales presentes en los procesos políticos (Pierson y Skocpol, 2008). Esta decisión permite visualizar el desarrollo institucional como resultado de procesos temporales concretos más que consecuencia de la búsqueda de su equilibrio o coordinación o la reproducción en él de un guion cultural hegemónico con el propósito de reducir la incertidumbre.

\section{El contexto y el análisis de las instituciones}

$\mathrm{Al}$ igual que otros enfoques institucionalistas, como el de la elección racional y el sociológico, ${ }^{6}$ los institucionalistas históricos también consideran que las instituciones

\footnotetext{
${ }^{2}$ Es el caso de los efectos de tradiciones administrativas de corte clientelista o meritocráticas en las reformas de personal, problema sustantivo abordado por Parrado y Salvador (2011), en el análisis de la institucionalización de la meritocracia en agencias reguladoras de América Latina.

${ }^{3}$ Distintas definiciones se le han asignado al término path dependence. En el presente artículo, se destaca la concepción que Pierson (2003) toma de Arthur (1994), David (2000) y Hacker (2002). Se refiere a procesos sociales dinámicos que involucran irreversibilidades (retroalimentación positiva), los cuales generan múltiples resultados posibles dependiendo de la secuencia específica en la cual los eventos se desarrollen. Krasner et al. (1984) plantean que una, vez se toma un camino, este canaliza los futuros desarrollos.

${ }^{4}$ Para Pierson (2003), la secuencia o el ordenamiento en el tiempo de los eventos y de los procesos políticos tiene un efecto significativo en los resultados. Las tempranas etapas en una secuencia pueden ubicar aspectos específicos de los sistemas políticos en distintos caminos, los cuales son reforzados con el paso del tiempo. Esto implica una noción de causalidad histórica, en la que un evento temprano activa un proceso autoperpetuante; de forma simple, la causa y el efecto se hallan unidos por la historia.

${ }^{5}$ Capoccia y Kelemen (2007) definen la coyuntura crítica como una situación en la cual durante un periodo relativamente corto se eleva sustancialmente la probabilidad de que los actores puedan incidir sobre los resultados de sus preferencias, en comparación con la probabilidad que tenían antes y después de la coyuntura. El anterior escenario es posible cuando el peso de los factores estructurales (económicos, políticos, culturales, ideológicos y organizacionales) reduce significativamente su influencia sobre la acción política y los actores se encuentran con una gama más amplia de opciones para decidir en favor del cambio institucional o la restauración del statu quo que las que tenían en la fase de coyuntura precrítica o puedan tener en la poscoyuntura crítica. La coyuntura puede terminar con la puesta en marcha de un proceso de cierre o dependencia de camino (path dependence) que limita las opciones futuras.

${ }^{6}$ El institucionalismo histórico, el institucionalismo de la elección racional y el institucionalismo sociológico nacen como reacción a las perspectivas conductistas de gran influencia en las décadas de 1960 y 1970 . Las tres perspectivas, desde visiones muy diferentes de la vida política, se fijaron como propósito aclarar el papel que las instituciones desempeñan en el moldeamiento de los resultados políticos y sociales. Los institucionalistas de la elección racional argumentan que las instituciones políticas concebidas como conjunto de reglamentaciones estructuran las interacciones de los actores relevantes y así ayudan a reducir la incertidumbre en el comportamiento de los demás (dilemas de acción colectiva). Dada la naturaleza egoísta de los actores, su comportamiento frente a los incentivos y las restricciones de las instituciones es instrumental y calculador (estratégico), está en función de la maximización de sus preferencias (Hall y Taylor, 1999; Peters, 2003). Desde el campo del institucionalismo sociológico, se plantea que las instituciones, además de reglas y procedimientos, son, sobre todo, prácticas culturales, es decir, pautas cognoscitivas, sistemas de simbología y patrones morales, que proporcionan los marcos de significación que orientan la acción política. Los marcos mencionados son resultado de los procesos
} 
influyen sobre el comportamiento político y dan forma a procesos que van desde la toma de decisiones de los actores poderosos de un sistema político hasta las movilizaciones que realizan las organizaciones sociales. Sin embargo, la forma como los históricos analizan las instituciones los distancia de otros enfoques institucionales: primero, el foco de su atención no es saber cómo determinadas reglas de juego ayudan a resolver problemas de acción colectiva, con el fin de reducir la incertidumbre en la sociedad, como lo hacen los investigadores de la elección racional, sino analizar la interacción entre instituciones y entre organizaciones e instituciones en contextos macro y los resultados que ese juego de intersecciones produce. Este enfoque se sustenta en la idea de que concibe las instituciones como fenómenos relacionales, razón que los obliga a estudiar sus vínculos con el contexto político y social en el cual están inmersos para poder explicarlas (Thelen, 1999). Segundo, van más allá de las explicaciones funcionalistas del desarrollo institucional (la lógica de las consecuencias), para darles relevancia causal a las secuencias o los procesos temporales, es decir, a los efectos a largo plazo de las decisiones institucionales, que los conciben como productos de procesos sociales ("preferencias congeladas") (Riker, 1991) o de conflictos previos (Pierson y Skocpol, 2008). Su interés por el estudio del desarrollo institucional los lleva a detenerse en las consecuencias no intencionales a largo plazo de elecciones políticas y conflictos anteriores (Pierson y Skocpol, 2008). A aquellas las enfocan como resultado de la interacción de procesos diferentes, donde varios factores institucionales, organizacionales y estratégicos se cruzan y se afectan mutuamente a lo largo del tiempo (Hay, 1997; Steinmo, 2001). Tercero, las instituciones son reconstruidas en el tiempo, es decir, las instituciones no solo se reproducen, sino que también cambian. Y esto ocurre cuando nuevas reglas son introducidas para responder a presiones endógenas o exógenas, sin reemplazar las preexistentes. En cualquier caso, es plausible que las decisiones originales incidan fuertemente en el funcionamiento actual de la institución, pero, igualmente, que las nuevas reglas logren desplazar las antiguas y dar origen a un cambio institucional transformador (Thelen, 1999, 2000; Thelen y Streck, 2005).

\section{Las coaliciones políticas y el cambio de las instituciones}

El origen, la estabilidad y el cambio de las instituciones y las políticas están relacionados con coaliciones políticas, que se constituyen deliberadamente o surgen de manera inesperada en el curso de la vida política. La capacidad de las coaliciones políticas para incidir en la dirección de las instituciones está relacionada con el poder relativo de los actores que las conforman (Mahoney y Thelen, 2009). Dicho poder son los recursos de acción que les permiten influir sobre los resultados de los procesos políticos; incluyen características personales, el control de recursos físicos, como el dinero, la tierra, la tecnología y el

de interpretación que realizan los actores políticos. Desde una posición crítica, se le señala al institucionalismo sociológico que las prácticas culturales también son propiciadas por los procesos de discusión (Hall y Taylor, 1999). 
acceso privilegiado a la información. Sin embargo, en la arena política, los recursos de acción que más interesan a los actores son los políticos. Estos son distribuidos con los arreglos institucionales cuando definen competencias, otorgan o limitan derechos de participación, de veto, y consagran la autonomía en la toma de decisiones (Scharpf, 1997).

Los anteriores recursos son necesarios para la configuración de la capacidad estratégica de los actores políticos y, por consiguiente, de las coaliciones políticas; sin embargo, no son suficientes. Es indispensable, primero, la dimensión cognitiva, es decir que los actores políticos relevantes en una coalición converjan en sus visiones y explicaciones. La mayor o menor capacidad estratégica está relacionada con la convergencia o divergencia de visiones e interpretaciones de los procesos políticos. Segundo, la capacidad para la acción estratégica también presupone la dimensión evaluadora o integradora de preferencias, esto es, la disposición para aceptar algunas pérdidas, con el objeto de obtener algunas ganancias totales más grandes o evitar pérdidas totales mayores (Scharpf, 1997). Esto explica por qué los resultados institucionales no siempre reflejan los objetivos de un grupo en particular. Ellos pueden mostrar un resultado no esperado, producto de un conflicto entre actores o consecuencia de "compromisos ambiguos", que se apartan de los objetivos sustantivos (Schikler, 2001; Palier, 2005).

Los grupos o coaliciones dominantes tienden a diseñar las instituciones que correspondan estrechamente a sus preferencias institucionales. Sin embargo, el papel de asignar poderes es una fuente generadora de tensiones (la lucha por el poder) que debilita la idea que muestra el desarrollo institucional como un proceso automático, perpetuo y de autorrefuerzo de las reglas y procedimientos. Esto vuelve vulnerables y controvertibles los acuerdos a causa de las dinámicas específicas de las coaliciones que son siempre sensibles a los cambios. La estabilidad no se basa solo en la acumulación, sino también en la movilización permanente de los recursos políticos (apoyos) y en la búsqueda de solución a las ambigüedades de las instituciones (Mahoney y Thelen, 2009). En síntesis, los cambios en el equilibrio de poder pueden propiciar la formación de coaliciones políticas interesadas en impulsar cambios o regresiones institucionales. El desequilibrio en el poder se puede expresar bajo la forma de cambios en la correlación de fuerzas, en divisiones entre las élites políticas por "efectos distributivos", en el uso de recursos de poder de unas instituciones para favorecer a otras y en la emergencia de fuerzas tradicionalmente subordinadas con capacidades estratégicas para desplazar los acuerdos hegemónicos (Mahoney y Thelen, 2009).

\section{Las estrategias de investigación: el método histórico comparativo}

El punto de partida del método histórico comparativo es el análisis de casos individuales a partir de los cuales se formulan hipótesis que ayudan a explicar las diferencias halladas, que no son otra cosa que los mecanismos causales presentes en patrones empíricos. Se 
trata de un método inductivo y microfundacional que exige trabajo empírico, para explicar cómo los actores se configuran históricamente, cómo definen sus preferencias y percepciones y cómo construyen sus capacidades usando sus recursos para actuar estratégicamente con sus pares. Al aplicar el método histórico comparativo, lo que buscan los académicos institucionalistas es ir más allá de la particularidad histórica y acercarse a la generalización teórica, sin pretender alcanzar el conocimiento universal. Esto explica su interés por construir teorías de rango medio (un rango limitado de casos unificados en el tiempo y en el espacio), a través del contraste de proposiciones teóricas con los fenómenos empíricos observados (Thelen, 1999, 2006). No se trata de descubrir leyes que expliquen la vida política y predecir el comportamiento político con la ayuda de modelos (teoría de la falsación). La prelación de los institucionalistas históricos es comprender los resultados reales, no la esencia de los principios teóricos o demostrar que en un fenómeno o una parte de él está presente el funcionamiento de un principio lógico, como la estabilidad o el equilibrio de las reglas de juego. Su interés es explicar por qué los sistemas políticos se mueven de un equilibrio a otro, no predecir el cambio (Steinmo, 2001).

En resumidas cuentas, el interés de los investigadores es analizar un proceso a lo largo del tiempo para hallar las conexiones causales entre variables, incluidas las relaciones temporales. En sus estudios, las instituciones no son las únicas variables explicativas. Para evitar ser capturados por la teoría (presunciones teóricas como las de la elección racional), la metodología (amarrada a la presunción teórica: actores estratégicos fijos, al igual que las preferencias y contextos (legislaturas) o por una técnica dada o fuentes de datos (encuestas sociales), el enfoque institucionalista toma como objeto de análisis los grandes problemas del mundo real, lo cual lo obliga a combinar distintas perspectivas teóricas, metodológicas y fuentes de información. Esto le da a su literatura un carácter pluralista (Pierson y Skocpol, 2008).

Frente a la crítica que recibe el institucionalismo histórico por seleccionar deliberadamente los estudios de caso y un número pequeño de temas sustantivos, que supuestamente le restan validez para hacer ciencia social acumulativa, los académicos responden que el estudio de problemas significativos facilita la acumulación del conocimiento, factor clave para el progreso de una comunidad científica; favorece el reexamen de los casos y las hipótesis por nuevos investigadores; permite refutar argumentos y refinar otros; descubrir nuevas líneas de argumentación causal y extender conclusiones a distintas épocas y regiones (Pierson y Skocpol, 2008).

Mientras los investigadores de la elección racional focalizan su agenda de trabajo en problemas generados en su teoría principal, al igual que sus métodos de indagación, los históricos generan conocimientos que dialogan con los grandes problemas sociales y tratan agregados sociales mayores, interrogan sobre amplios contextos y transformaciones a largo plazo. En síntesis, combinan perspectivas teóricas, estrategias metodológicas y 
usan varias fuentes de información. Con esta práctica, convierten el pluralismo teórico y metodológico en uno de los atributos sobresalientes del análisis histórico institucional (Pierson y Skocpol, 2008).

En suma, con el repertorio de ideas descritas, se puede estudiar la evolución institucional de las organizaciones del Estado. Dicho desarrollo se concibe: 1) como un problema sustantivo, cuya evolución institucional está conectada con un contexto político (reglas formales e informales); 2) un resultado de procesos históricos concretos como coyunturas críticas y fenómenos de dependencia de camino (la persistencia de politizados patrones de personal en la administración estatal), pero igualmente de cambio bajo una poscoyuntura crítica; 3) un producto de la interacción de organizaciones políticas y sociales, como los Gobiernos nacionales, los congresos, los partidos políticos, las cortes constitucionales, las contralorías generales, los sindicatos y las entidades multilaterales; 4) una consecuencia no intencional, producto de la naturaleza conflictiva de los procesos históricos y del carácter contradictorio e inestable de los acuerdos institucionales que construyen actores con recursos discursivos y de poder diferentes, con el fin de favorecer la formación de coaliciones políticas.

\section{El institucionalismo discursivo ${ }^{7}$ y su influencia en las ideas del desarrollo institucional}

Las ideas tienen su contexto, que no es otro distinto de las estructuras institucionales que ponen límites a los actores políticos cuando estos les asignan o reasignan sus sentidos. Se trata de estructuras de sentidos, cuya permanencia o cambio está determinado, primero, por su fondo o repertorio de ideas (conocimientos y disposiciones), que les ayuda a actuar en un contexto de significados, con el fin de reinventarse para sortear las presiones internas y externas hacia el cambio; y segundo, por las habilidades discursivas (capacidad de persuasión) de los actores interesados en su continuidad o transformación.

El contenido de las ideas incide en el cambio de las reglas, porque ellas son estructuras y construcciones de sentido, es decir, llevan incorporadas las ideas (cognitivas y normativas) que les dan su orientación. Cambiar un arreglo institucional es cambiar la idea o las ideas que le dan su sentido o direccionamiento (cambio ideacional). Es, por tanto, un cambio que se origina en las reglas y no por fuera de ellas (Schmidt, 2010). Las instituciones concebidas como ideas o estructuras discursivas les restringen y les posibilitan a los actores la reinterpretación de su significado (hablar y pensar sobre ellas). Tanto la limitación como la apertura del contenido sustantivo de las ideas presentes en

\footnotetext{
${ }^{7}$ El institucionalismo discursivo es considerado el más reciente campo teórico entre los estudios neoinstitucionales en la ciencia política. Vivien Schmidt, profesora de la Universidad de Boston (Massachusetts), sobresale entre las académicas que vienen interrogando, con argumentos del institucionalismo discursivo, la influencia de las ideas en el cambio institucional.
} 
una institución están condicionadas por el grado de ambigüedad y confusión. Cuanto menos ambigüedad, las ideas, consideradas como mapas de ruta, podrán orientar con mayor efectividad la selección de preferencias si estas no han sido escogidas aún, y si ya lo fueron, ayudarán también a buscar opciones entre ellas.

Las decisiones sobre la selección de preferencias que se dan en contextos materiales, caracterizados por altos niveles de incertidumbre, pueden llevar al cambio de las ideas que los actores tienen sobre determinada realidad y, subsecuentemente, a la variación de preferencias y estrategias. La respuesta puede favorecer la formación de nuevas coaliciones políticas, cuyas acciones colectivas se orienten con nuevas ideas y guiones que propician el desplazamiento de viejas instituciones.

La ambigüedad refleja la superposición de ideas en las estructuras institucionales; no se trata solo de un añadido de reglas y mecanismos, sino también de un agregado de sentidos. Por tanto, desplazar una regla de un sistema social es desplazar una idea u orientación institucional. Fortalecer las posibilidades de veto contra una institución, y elevar su nivel de discrecionalidad, significa bloquear la institucionalización del contenido de una idea institucional. Las instituciones no solo asignan poderes de manera asimétrica en el sistema político, sino que también son portadoras de ideas o "memoria colectiva”, que las convierte en objetos de confianza o desconfianza, que, con el tiempo, ante fenómenos como la disfuncionalidad o cambio de rendimiento, pueden favorecer el cambio de las ideas que los actores tienen de ellas (Schmidt, 2010).

\section{El discurso como un proceso interactivo}

A través del discurso, el contenido sustantivo de las ideas se comunica y se intercambia. Su método es el de la persuasión. Apoyados en él, los actores superan las explicaciones respecto de las preferencias y los intereses fijos, y se construyen consensos o comprensiones compartidas en torno a intereses y valores políticos. Con la deliberación, se reduce el impacto de la interacción basada en la manipulación y en las posiciones de poder, y se eleva el poder de las ideas y el discurso. Las ideas son importantes recursos de poder, porque inciden en las percepciones que favorecen o no el ejercicio de los poderes que tienen su origen en posiciones estructurales.

El proceso discursivo tiene dos dimensiones: 1) un proceso discursivo coordinado orientado a la construcción de ideas, en el que interviene una gama amplia de actores políticos: "comunidades epistémicas" de élite con ideas compartidas, "coaliciones" de defensa, ideas compartidas, "redes" impugnadoras o catalizadoras de ideas y 2) un proceso discursivo comunicativo de las ideas, en el cual se delibera y se legitiman preferencias y cursos de acción. En esta interacción discursiva, intervienen líderes políticos involucrados en procesos de persuasión política a los ciudadanos y miembros de la sociedad civil. Las ideas cognitivas y normativas se representan y se comunican a 
través de mecanismos, como las narraciones, los mitos, las memorias colectivas. Con ellos, se tematizan los problemas, sus orígenes y soluciones, todo con el fin de producir un cambio en las creencias (Schmidt, 2010).

El institucionalismo discursivo enriquece los argumentos institucionalistas históricos de Thelen, en especial su concepto de discurso ideológico, que, al lado de la noción de coaliciones políticas, son los mecanismos centrales del desarrollo institucional, es decir, la estabilidad y el cambio.

\section{La estabilidad y el cambio institucional en el enfoque institucional histórico}

En la mayoría de los enfoques institucionales, el estudio del cambio no es un tema central. El interés de los académicos que los incorporan a sus marcos de análisis en general se orienta a construir explicaciones relacionadas con la continuidad de las instituciones. Así, por ejemplo, el objetivo de los teóricos de la elección racional es examinar las reglas de juego como mecanismos de coordinación, factores clave para mantener el equilibrio social. En igual sentido, los institucionalistas sociológicos le dan preferencia a la permanencia de las instituciones, definidas como interpretaciones compartidas que inciden en la forma como los actores perciben los problemas y buscan las soluciones. El cambio no es frecuente ni rutinario, porque es costoso y difícil. Cuando ocurre, probablemente es episódico, marcado por breves periodos de crisis o intervención decisiva, y seguido de periodos más largos de estabilidad o desarrollo dependiente de la trayectoria (Powell, 1999).

Las instituciones, más que resultado de un diseño deliberado, son patrones sociales que muestran un determinado proceso de reproducción. La tenaz resistencia de las estructuras institucionales las asocian con diferentes variables, tales como el ejercicio del poder de la élite y las interdependencias complejas que tejen las organizaciones, sobre todo a través de relaciones jerárquicas, que hacen muy costoso, desde el punto de vista político, financiero y cognoscitivo, la sustitución de los entramados institucionales (Powell, 1999).

En el campo de los institucionalistas históricos, los investigadores que les dan prevalencia a las preguntas relacionadas con estabilidad institucional tienden a ser los más representativos. Los trabajos realizados en las décadas de 1980 y 1990 muestran la influencia del modelo de equilibrio puntuado o intermitente, que, a juicio de Krasner et al. (1984), proviene de las investigaciones adelantadas en biología. En contraste con el concepto de evolución, que es visto como un proceso de cambio lento y continuo en el cual las instituciones se adaptan a las condiciones ambientales, en la metáfora del equilibrio puntuado el cambio es un fenómeno rápido y de corta duración seguido de largos periodos de estabilidad institucional. En este enfoque, los periodos de formación de una institución y los periodos de continuidad o persistencia, al igual que los factores causales que explican dichos estados, son diferentes. Las instituciones nacen en periodos de crisis 
(coyunturas críticas) como resultado de choques exógenos y, luego, a través de otros mecanismos, toman un camino que canaliza sus futuros desarrollos (Krasner et al., 1984).

Los argumentos más recientes sobre el cambio y la estabilidad institucional los presentan autores como North $(2001,2007)$ y Pierson $(2000,2004)$. Para el primero, el cambio se explica por razones utilitaristas o funcionalistas, o sea, para adecuar los marcos institucionales a las preferencias (incentivos) de los actores. Se trata de un proceso abrumadoramente incremental, porque la estructura institucional dominante (path dependence) impone fuertes restricciones al conjunto de decisiones disponibles para los reformadores cuando estos buscan innovar a fin de mejorar sus posiciones económicas y políticas. Se trata de una modalidad de cambio que por la vía de la acumulación puede transformar una matriz o patrón institucional. Para que se produzcan los cambios incrementales, es necesario que existan marcos institucionales que favorezcan nuevas negociaciones y compromisos entre los jugadores. En caso contrario, se alimenta la formación de coaliciones interesadas en promover el cambio mediante la confrontación violenta (North, 2001). El cambio abrupto y radical de las reglas formales, como resultado de una revolución o de la conquista, no está ausente, pero su emergencia suele ser ocasional y rápida (North, 2007).

La estabilidad de un marco institucional se logra con un conjunto de reglas formales, jerárquicas e informales (rutinas, costumbres, tradiciones y convenciones) que tienen una tenaz aptitud de supervivencia, porque se han vuelto parte de la conducta habitual. Concretamente, producen rendimientos crecientes y numerosos mediante mecanismos autorreforzadores, como los efectos de organización, aprendizaje y las expectativas adaptativas que reducen su incertidumbre (North, 2001). Los rendimientos crecientes forman el camino de dependencia y este impone el predominio de la evolución incremental; se trata de un cambio gradual mediante ajustes marginales continuos sobre la alteración radical de las reglas formales del juego (North, 2001). Las fuentes del cambio son en su mayoría factores endógenos, aunque los exógenos también pueden incidir en la innovación. El equilibrio institucional (la permanencia de un patrón institucional), resultado de las limitaciones institucionales formales e informales, se mantiene cuando ninguno de los actores con mayor fuerza negociadora considera ventajoso dedicar recursos a reestructurar los acuerdos o contratos existentes (North, 2001).

A manera de recapitulación, en las anteriores líneas se afirma:

1. En contraste con los teóricos del "equilibrio puntuado", para North el cambio continuo o incremental es la forma más habitual del desarrollo de las instituciones, y no el cambio radical o discontinuo, que también está presente en su marco de análisis, pero, al igual que los primeros, lo considera un fenómeno raro y fugaz.

2. El peso de las restricciones (costos de transacción) y de los incentivos (rendimientos crecientes) de las reglas del juego ayudan a configurar un camino de 
dependencia, que impone la modalidad de cambio incremental como la forma dominante del desarrollo institucional, es decir, el predominio de la estabilidad sobre el cambio. Sin embargo, como hecho notable, introduce a su perspectiva analítica la idea de que por la vía de la evolución (acumulación) se puede llegar a la transformación de las estructuras institucionales.

3. Los factores endógenos, como son las estructuras institucionales, pueden tener un rol central en los procesos de negociación entre los actores comprometidos en mantener o cambiar las reglas del juego.

4. Los mecanismos reforzadores de los patrones institucionales están separados de los mecanismos propiciadores de la evolución institucional. Esta postura guarda consonancia con la lógica de la consecuencia, donde la llave de la evolución institucional son los incentivos que las reglas ofrecen a los actores poderosos. Si estos los consideran ventajosos, la opción por el cambio se vuelve racional.

Pierson, al igual que North, aborda el concepto de la dependencia de trayectoria con argumentos sobre los llamados mecanismos de retornos crecientes (increasing returns). A estos los concibe como procesos sociales autorreafirmantes o de retroalimentación positiva de patrones de desarrollo institucional surgidos en tiempos formativos, como los que distinguen a las coyunturas críticas. Los procesos de retornos crecientes se caracterizan, en primer lugar, por la incertidumbre o equilibrio múltiple a causa de que los primeros eventos tienen un gran efecto que los hace más importantes que los posteriores, pero son parcialmente aleatorios, lo cual abre la ventana de posibilidades a variedad de resultados; en segundo lugar, por la inflexibilidad o inercia, pues, cuanto más se avance en un camino de desarrollo institucional mediante procesos de retornos crecientes, la retroalimentación positiva puede llevar a un único equilibrio que se resistirá al cambio; en tercer lugar, por la contingencia de eventos pequeños que se dan en etapas tempranas en una secuencia y que tienen incidencia en las elecciones futuras de los actores; $y$, en cuarto lugar, la ineficiencia potencial de un camino, pues, a largo plazo, el resultado que se encierra puede generar menores beneficios de los que habría brindado una alternativa rechazada (Pierson, 2000).

Desde la perspectiva de Pierson, varios son los mecanismos que pueden generar procesos de retornos crecientes:

1. La naturaleza colectiva de la actividad política lleva a que los actores políticos tiendan a adaptar sus expectativas al comportamiento de sus pares, pues no tenerlo en cuenta puede significarles costos inmensos (Olson, 1992). Los costos de iniciación para un nuevo arreglo institucional podrían ser muy elevados si se desconociera dicha dimensión, más aún cuando las decisiones políticas dependen 
de mecanismos de decisión colectiva respaldados por la autoridad (Pierson, 2000). Por tanto, las expectativas adaptativas tienden a darles continuidad a las reglas institucionales diseñadas en el pasado.

2. La principal actividad de la política es regular y coordinar el conflicto que nace entre los actores políticos por el acceso a los bienes públicos. Para lograrlo, estos adoptan instituciones formales (normas constitucionales y legales) vinculantes para todos y respaldadas por la fuerza coactiva del Estado. La estructura naciente al ponerse en práctica tiende a generar efectos de aprendizaje y coordinación que favorecen la construcción de compromisos entre numerosos actores. En estas condiciones, los esfuerzos por cambiar las reglas pueden resultar poco atractivos y, sí, muy costosos, para los firmantes de compromisos que producen réditos crecientes (Pierson, 2000).

3. El ejercicio de la autoridad política por actores específicos es otra fuente clave de retroalimentación positiva. Prevalidos de dicha autoridad, imponen arreglos institucionales que acrecientan su poder hasta hacerlo más asimétrico y menos visible (Pierson, 2000). Una mayor concentración del poder en manos de dichos actores políticos les facilita reproducir las instituciones que los mantienen como ganadores permanentes.

4. La interpretación que realizan los actores políticos de la vida política en un ambiente lleno de complejidad e impenetrabilidad también es susceptible de dependencia de camino. Ella tiende a sesgarse en favor de los "mapas mentales" existentes, donde solo son válidas las percepciones que los ratifican. Estos mapas corresponden a los puntos de vista básicos de la política: ideologías, enfoques de aspectos específicos del Gobierno, orientaciones hacia grupos o partidos, que una vez se establecen como camino dependiente son “difíciles” de olvidar. La ratificación en el tiempo de la interpretación “oficial” de las reglas institucionales que son compartidas con otros actores tiende a crear efectos de red y expectativas adaptables. Por eso, el desarrollo de otras interpretaciones tiene altos costos de iniciación y aprendizaje (Pierson, 2000).

Sustancialmente, para Pierson, los mecanismos de retorno crecientes son importantes, porque captan dos elementos clave de la dependencia de camino en los procesos políticos: primero, muestran con claridad cómo crecen a lo largo del tiempo, en ciertos contextos políticos, los costos de sustituir un diseño institucional por otro, lo cual refuerza su permanencia. Los mecanismos evidencian que la estabilidad es un rasgo de la vida política presente en variedad de prácticas organizativas. Dichas prácticas no excluyen el cambio, pero lo limitan, hasta que factores exógenos o endógenos erosionan los mecanismos que reproducen la continuidad y se dan las condiciones favorables para los momentos formativos de nuevos patrones de desarrollo institucional. Segundo, los retornos crecientes también le dan gran importancia a la centralidad de los procesos históricos, es decir, al 
ordenamiento temporal o secuencia específica de los eventos y procesos y sus efectos en la variación de la vida política. Por eso distingue tanto los momentos formativos como las coyunturas críticas o históricas de los periodos en los que se reafirman caminos dependientes.

Para cerrar este apartado dedicado a discutir los argumentos duros y blandos del concepto de dependencia de camino, con el fin de comprender la estabilidad (una dimensión imprescindible del desarrollo institucional), se subraya aquí, en primer término, que este concepto y, subsecuentemente, el de retornos crecientes, son importantes instrumentos cognitivos para interpretar y explicar una de las dimensiones clave de la naturaleza de las instituciones, como es su tendencia a permanecer regulando la vida política, una vez ellas han logrado posicionarse exitosamente frente a otros diseños alternativos. En segundo término, se considera que Pierson enriquece el análisis de la estabilidad política al sugerir la identificación de unos mecanismos de carácter político que explican la permanencia de las instituciones, que los busca en rasgos de la actividad política, tales como su carácter colectivo, la densidad de las instituciones políticas, la tendencia de la autoridad política a acrecentar en forma asimétrica el poder y la complejidad e impenetrabilidad de la vida política que obliga a la elaboración de marcos interpretativos, para definir y justificar los órdenes políticos y sociales.

Sin embargo, dentro del análisis de Pierson, al igual que en el de North, la estabilidad tiene mayor incidencia en el desarrollo de las instituciones que el cambio; no es casual entonces la abundancia de argumentos dedicados a describir y explicar por qué las reglas formales e informales tienden tenazmente a permanecer una vez han construido "camino al andar", sin importar si nacieron como resultado de una coyuntura crítica o de un proceso evolutivo. En esta investigación, se considera con Thelen que separar dentro de un análisis las dinámicas que explican la estabilidad de las del cambio es una limitación cognitiva que riñe con la naturaleza del desarrollo institucional que involucra indefectiblemente ambas dimensiones.

\section{Consideraciones finales}

Es indudable que se ha avanzado en la construcción de herramientas conceptuales útiles para el estudio del desarrollo institucional, visto como un proceso que involucra la permanencia y el cambio en las estructuras institucionales. Como ya se señaló, el análisis de la estabilidad en la literatura aporta conceptos como dependencia de camino (path dependence) y rendimientos crecientes (increasing returns), que describen mecanismos con los cuales una elección o una institución del pasado restringe con más fuerza las decisiones presentes. Entre los mecanismos sobresalen los costos de inversión, los efectos de aprendizaje, de coordinación y de anticipación (Krasner et al., 1984; North, 1990; Pierson, 2000).

Igual importancia tienen los conceptos de jerarquización de las reglas formales y la funcionalidad y legitimidad de las instituciones formales e informales. El primero muestra que cuanto más jerarquía tenga una regla (constitucional, legal, operativa) mayor es 
el costo de cambiarla. Por tanto, aumenta la estabilidad de expectativas mutuas entre los individuos que interactúan de acuerdo con un conjunto de reglas (Kiser y Ostrom, 2000; Ostrom, 2000). La funcionalidad y legitimidad también operan como mecanismos que pueden llevar a la informalización y “naturalización” de las reglas y, en consecuencia, a su tenaz aptitud de supervivencia (North, 2001). El análisis del cambio también tiene sus herramientas conceptuales. Sobresalen los conceptos de coaliciones políticas y los discursos ideológicos, como los recursos más poderosos para viabilizar el cambio institucional (Thelen, 1999; Schmidt, 2010). Sin embargo, tanto los mecanismos que han sido definidos para el estudio de la estabilidad, como los adoptados para el examen del cambio, tienden a usarse en forma separada en las investigaciones que interrogan sobre el desarrollo institucional.

En la primera década del siglo XXI, emerge una línea de investigación bajo el liderazgo académico de Kathlen Thelen, que replantea la visión de la estabilidad y el cambio como dimensiones separadas del desarrollo institucional y propone un análisis unificado, que incorpora los conceptos de camino de dependencia y evolución institucional (Thelen, 1999, 2006; Thelen, K. y Streck, 2005). En el esquema de Thelen, los procesos de cambio pueden ser incrementales o abruptos, y los resultados pueden orientarse a la continuidad o a la discontinuidad. El cambio a gran escala (transformador) se puede lograr no solo en contextos de coyunturas críticas, sino también en escenarios de aparente estabilidad, como resultado de la acumulación a lo largo de periodos de sutiles cambios incrementales. Más aún, bajo los contextos “inerciales” se pueden introducir nuevas reglas, sin que ellas pasen por el filtro de la agenda gubernamental, y esto puede ocurrir cuando los arreglos formales existentes no interpretan las presiones sociales (Thelen y Streeck, 2005).

Los periodos de estabilidad y cambio no están separados; tampoco hay periodos caracterizados por la primacía de la agencia o la estructura. La reproducción y la transformación institucional están condicionadas por los cambios que se producen en las coaliciones políticas que les sirven de soporte. No siempre las coaliciones ganan las batallas clave de una reforma, pero su accionar puede frenar o quitarles fuerza a ciertos procesos. Son ellas las encargadas de renegociar aspectos del antiguo sistema y de mantener algunas características (Thelen, 2006).

Ahora bien, el análisis de Thelen se centra en el cambio evolutivo. Se trata de un cambio endógeno, impulsado desde el interior de las instituciones por actores que, a través de la reinterpretación y el redireccionamiento de las reglas existentes, buscan debilitarlas para posicionar las de sus preferencias (Thelen y Streeck, 2005). Es un cambio gradual, cuyos resultados se acumulan. Es gradual, porque las instituciones preexistentes, así se estén reformando o disolviendo, limitan y condicionan su desarrollo futuro. Esto es posible porque las fuerzas políticas y sociales que las defienden y las que buscan cambiarlas no tienen la suficiente capacidad para imponer unilateralmente su propio diseño institucional. 
En estas condiciones, cobra fuerza la estrategia de la renegociación (Thelen y Streeck, 2005). Se trata de los cambios lentos, sutiles y graduales que registran las instituciones una vez son creadas, y que, al igual que los cambios abruptos, también moldean el comportamiento de los actores sociales y políticos. Se trata de cambios que, por la vía de los efectos acumulativos, se pueden convertir en transformadores (Mahoney y Thelen, 2009). En otras palabras, es una modalidad de cambio institucional que combina elementos de cierre, con nuevos desarrollos que no empujan más allá en la misma dirección, pero sí alteran la trayectoria general del desarrollo institucional y de la política (Thelen, 2006).

Como ya se dijo, el concepto de coyunturas críticas también está presente dentro del análisis de Thelen. Describe una situación que se presenta cuando las coaliciones políticas que favorecen la reproducción de lógicas institucionales específicas (path dependence) pierden la capacidad para defenderlas, situación que las vuelve vulnerables a las presiones hacia el cambio provenientes de procesos sociales endógenos y exógenos (Collier y Collier, 2006; Mahoney y Thelen, 2009). Las coyunturas críticas son escenarios propicios para que los problemas que ya no se procesan en las instituciones sean llevados por nuevos actores a las agendas de elección constitucional y colectiva, contextos donde el tema del cambio institucional discontinuo tiene mayores probabilidades para materializarse en reglas formales, incluidas las de la Constitución Política, en leyes de amplia mayoría, en leyes de mayorías simples y decretos gubernamentales (Ostrom, 1999).

Las coyunturas críticas son también momentos de alta tensión y de grandes retos para los arreglos institucionales existentes, pero, igualmente, escenarios para su reafirmación (Capoccia y Kelemen, 2007). Y son resultado de procesos que tienen su origen en el seno de las mismas instituciones, pues son sus propiedades (asignación de poder y ambigüedades) las que facilitan que las presiones exógenas (elementos del entorno social o institucional) catalicen, socaven y aceleren sus procesos de transformación (Panebianco, 1982). Para concluir, se señala que las ideas de Thelen sobre el cambio institucional, y en especial la evolución institucional, son piezas centrales para la construcción de marcos de análisis, con los cuales se busca describir y explicar el desarrollo de las instituciones políticas.

\section{Referencias}

Capoccia, G. y Kelemen, R. D. (2007). The study of critical junctures theory, narrative, and counterfactuals in historical institucionalism theory. Washington DC: University of Oxford.

Collier, R. B. y Collier D. (2006). Shaping the political arena: Critical junctures, the labor movement, and regime dynamics in Latin America. Notre Dame, Indiana: University of Notre Dame Press. 
Hall, P. y Taylor, R. (1999). La ciencia política y los tres nuevos institucionalismos. Revista Conmemorativa del Colegio Nacional de Ciencias Políticas y Administración Pública, 15-54.

Hay, C. (1997). Estructura y actuación (agency). En D. Marsh y G. Stoker (eds.), Teoría y métodos de la ciencia política (pp. 197-213). Madrid: Alianza Editorial.

Kiser, L. L. y Ostrom, E. (2000). The three worlds of action: A metatheoretical synthesis of institutional approaches. Polycentric Games and Institutions, 1, 56-88.

Krasner, S. D., Nordlinger, E., Geertz, C., Skowronek, S., Tilly, C., Grew, R. y Trimberger, E. K. (1984). Approaches to the state: Alternative conceptions and historical dynamics. Comparative Politics, 16(2), 223-246.

Mahoney, J. y Thelen, K. (2009). A theory of gradual institutional in forthcoming. En J. Mahoney y K. Thelen (eds.). Explaining institutional change: Ambiguity, agency, and power (pp. 1-35). Cambridge: Cambridge University Press.

North, D. (1994). Estructura y cambio en la historia económica. Madrid: Alianza.

North, D. (2001). Instituciones, cambio institucional y desempeño económico. México: Fondo de Cultura Económica.

North, D. (2007). Para entender el proceso de cambio económico. Bogotá: Norma.

Olson, M. (1992). La lógica de la acción colectiva: bienes públicos y la teoría de grupos. México: Limusa.

Orren, K. y Skowronek, S. (1999). Orden y tiempo en el estudio de las instituciones: un alegato a favor del enfoque histórico. En La ciencia política en la historia: programas de investigación y tradiciones políticas (pp. 378-405). Madrid: Istmo.

Ostrom, E. (1999). Institutional rational choice: An Assessment of the institutional analysis and development framework. En P. A. Sabatier (ed.), Theories of the policy process (pp. 35-72). Boulder: Westview Press.

Ostrom, E. (2000). El gobierno de los bienes comunes: la evolución de las instituciones de la acción colectiva. México: Fondo de Cultura Económica.

Palier, B. (2005). Tracing the political processes of path-breaking changes in french social policy. En W. Streeck y K. A. Thelen (eds.), Continuity and discontinuity in institutional analysis (pp. 127-44). Oxford: Oxford University Press.

Panebianco, A. (1982). Modelos de partido. Madrid: Alianza Editorial.

Parrado, S. y Salvador, M. (2011). The institutionalization of meritocracy in Latin American regulatory agencies. International Review of Administrative Sciences, $77(4), 687-712$. 
Peters, B. G. (2003). El nuevo institucionalismo. Barcelona: Gedisa.

Pierson, P. (2000). Increasing returns, path dependence, and the study of politics. American Political Science Review, 94(02), 251-267.

Pierson, P. (2004). Politics in time: History, institutions, and social analysis. Princeton: Princeton University Pres.

Pierson, P. y Skocpol, T. (2008). El institucionalismo histórico en la ciencia política contemporánea. Revista Uruguaya de Ciencia Política, 17(1), 7-38.

Powell, W.W. (1999). Expansión del análisis institucional. En W. Powell y P. J. DiMaggio (comps.), El nuevo institucionalismo en el análisis organizacional. México: Fondo de Cultura Económica.

Riker, W. (1991). Implicaciones del desequilibrio de la regla de la mayoría para el estudio de las instituciones. En J. M. Colomer, Lecturas de teoría política positiva. Madrid: Instituto de Estudios Fiscales.

Scharpf, F. W. (1997). Games real actors play: Actor-centered institutionalism in policy research. Boulder, Colo.: Westview Press.

Scharpf, F. W. (2000). Institutions in comparative policy research. Comparative Political Studies, 33(6-7), 762-790.

Schickler, E. (2001). Dsjointed pluralism: Institutional innovation and the development of the U.S. Congress. Princeton, NJ: Princeton University Press.

Schmidt, V. A. (2010). Taking ideas and discourse seriously: explaining change through discursive institutionalism as the fourth 'new institutionalism'. European Political Science Review, 2(01), 1-25.

Steinmo, S. (2001). The new institutionalism. En B. Clark y J. Foweraker (eds.), The encyclopedia of democratic thought. Londres: Routlege.

Steinmo, S. (2013). Institucionalismo histórico. En D. Della Porta y M. Keating (eds.), Enfoques y metodologías en las ciencias sociales: una perspectiva pluralista (pp. 131-151). Madrid: Akal.

Thelen, K. (1999). Historical institutionalism in comparative politics. Annual Review of Political Science, 2(1), 369-404.

Thelen, K. (2006). How institutions evolve: Insights from comparative historical analysis. En J. Mahoney y D. Rueschemeyer (eds.), Comparative historical analysis in the social sciences (pp. 208-240). Cambridge: Cambridge University Press. 
Thelen, K. y Streck (2005). Institutional change in advanced political economies. En W. Streeck y K. A. Thelen, Beyond continuity: Institutional change in advanced political economies (pp. 1-40). Oxford: Oxford University Press.

Zurbriggen, C. (2006). El institucionalismo centrado en los actores: una perspectiva analítica en el estudio de las políticas públicas. Revista de Ciencia Política (Santiago), 26(1), 67-83. 